\section{RSP}

http://www.rsp.fsp.usp.br/
Revista de Saúde Pública

\title{
Factors associated with prenatal care and HIV and syphilis testing during pregnancy in primary health care
}

\author{
Cláudia Helena Soares de Morais Freitas' ${ }^{1}$ iD, Franklin Delano Soares Forte ${ }^{\mathrm{i}}$ iD, Angelo \\ Giuseppe Roncalli" iD, Maria Helena Rodrigues Galvão"I (iD, Ardigleusa Alves Coelho"II (iD, \\ Sonia Maria Ferreira Dias ${ }^{\mathrm{IV}}$ (ID \\ I Universidade Federal da Paraíba. Departamento de Clínica e Odontologia Social. João Pessoa, PB, Brasil. \\ " Universidade Federal do Rio Grande do Norte. Programa de Pós-Graduação em Saúde Coletiva. Natal, RN, Brasil \\ III Universidade Estadual da Paraíba. Departamento de Enfermagem. Campina Grande, PB, Brasil \\ iv Universidade Nova de Lisboa. Instituto de Higiene e Medicina Tropical. Lisboa, Portugal
}

\section{Correspondence: \\ Cláudia Helena Soares de Morais Freitas \\ Universidade Federal da Paraíba, \\ Departamento de Clínica e \\ Odontologia Social, Cidade \\ Universitária \\ 58.051-900 João Pessoa, PB, Brasil E-mail: chsmfreitas@hotmail.com}

Received: Sep 11, 2018

Approved: Jan 21, 2019

How to cite: Freitas CHSM, Forte FDS, Roncalli AG, Galvão MHR, Coelho AA, Dias SMF. Factors associated with prenatal care and HIV and syphilis testing during pregnancy in primary health care. Rev Saude Publica. 2019;53:76.

Copyright: This is an open-access article distributed under the terms of the Creative Commons Attribution License, which permits unrestricted use, distribution, and reproduction in any medium, provided that the original author and source are credited.

\section{ABSTRACT}

OBJECTIVE: To evaluate the factors associated with HIV and syphilis testing during pregnancy in Brazil.

METHODS: This was an ecological study covering all Brazilian municipalities evaluated by the second cycle of the National Program for Access and Quality Improvement in Primary Care, 2013-2014. The dependent variables were based on prenatal care access: prenatal care appointments, and HIV and syphilis tests during prenatal care. The independent variables were compared with demographic and social characteristics. Bivariate analysis was performed assessing the three outcomes with the independent variables. Variables with significant associations in this bivariate analysis were fit in a Poisson multiple regression analysis with robust variance to obtain adjusted estimates.

RESULTS: Poisson regression analysis showed a statistically significant association with the variables "less than eight years of study" [prevalence ratio $(\mathrm{PR})=1.31$; 95\%CI 1.19-1.45; $\mathrm{p}<0.001$ ] and "participants of the cash transfer program" ( $\mathrm{PR}=0.80$; 95\%CI 0.72-0.88; $\mathrm{p}<0.001$ ) for the outcome of "having less than six prenatal care appointments" and individual variables. A statistically significant association was found for "participants of the cash transfer program" $(\mathrm{PR}=1.43 ; 95 \% \mathrm{CI} 1.19-1.72 ; \mathrm{p}<0.001)$ regarding the outcome from the comparison between HIV testing absence during prenatal care and demographic and social characteristics. The absence of syphilis testing during prenatal care, and demographic and social characteristics presented a statistically significant association for the education level variable "less than eight years of study" (PR $=1.75$; 95\%CI 1.56-1.96; $\mathrm{p}<0.001$ ) and "participants of the cash transfer program" $(\mathrm{PR}=1.21,95 \% \mathrm{CI} 1.07-1.36 ; \mathrm{p}<0.001)$.

CONCLUSIONS: The individual factors were associated with prenatal care appointments and HIV and syphilis tests in Brazilian pregnant women. They show missed opportunities for diagnosing HIV and syphilis infection during prenatal care and indicate weaknesses in the quality of maternal health care services to eliminate mother-to-child transmission.

DESCRIPTORS: Prenatal Care. HIV Infections, diagnosis. AIDS Serodiagnosis. Syphilis, Congenital, diagnosis. Infectious Disease Transmission, Vertical, prevention \& control. Health Care Quality, Access, and Evaluation. 


\section{INTRODUCTION}

Maternal syphilis and HIV infections are a global concern and important public health problems. The overall number of children living with HIV has decreased since antiretroviral medicines to HIV-positive pregnant women were provided (over 3.0 to 2.6 million) ${ }^{1}$. Mother-to-child transmission rate in Latin America and The Caribbean has decreased from $15 \%$ to $8 \%$. The estimated coverage of antiretroviral therapy in HIV-positive pregnant women for mother-to-child transmission prevention between 2010 and 2015 increased by $52 \%$ to $88 \%^{2}$.

Nearly 1 million pregnant women are infected by syphilis worldwide ${ }^{1}$. A growing rate of 1.7 cases per 1,000 live births has been reported, and 22,000 cases of congenital syphilis were estimated in the Americas in 2015. In Brazil, the congenital syphilis rate per 1,000 live births was 6.49 in 2015, and HIV prevalence in females aged 15-49 was $0.4(0.3-0.6)^{2,3}$.

Syphilis/HIV identification in pregnant women is essential for vertical transmission prevention and treatment. Prenatal care services are the entry point for the elimination of mother-to-child transmission. A combined approach to these diseases is recommended by the WHO (World Health Organization) for promoting better maternal and child health ${ }^{4,5}$.

Early detection and administration of suitable therapies are central interventions to prevent congenital syphilis ${ }^{5}$. Interventions to prevent mother-to-child HIV transmission include early access to quality prenatal care, HIV testing, counseling and antiretroviral therapy ${ }^{6}$ Despite the expansion of prenatal syphilis screening programs, many barriers limit maternal syphilis screening and treatment efforts around the world, and therefore their potential solutions ${ }^{7,8}$. Syphilis continues to be a major public health concern in developing countries.

In Brazil, the health policy for AIDS and congenital syphilis ${ }^{9}$ recommends specific actions and goals to improve dissemination control, including increasing HIV and syphilis test coverage during prenatal care. Several studies in hospitals and in Primary Health Care ${ }^{10-14}$ observed that HIV and syphilis test coverage has increased in all Brazilian regions. Despite the contributions, no nationwide studies in Primary Health Care have been found in Brazil.

Some studies have shown no difference in congenital syphilis and HIV incidence in areas with greater coverage of Family Health Strategy units ${ }^{15-18}$. In addition, they report failures in primary $\operatorname{care}^{17}$. These findings reinforce the importance of a national study assessing primary care quality ${ }^{16,19,20}$.

Although the Brazilian government has invested in the availability of prevention and treatment actions in this area, few national studies were conducted with pregnant women with access to prenatal care and adequately monitored for the number of appointments, HIV and syphilis testing, and counseling. This study aims to evaluate the factors associated with non-testing of HIV and syphilis during pregnancy in primary health care in Brazil.

\section{METHODS}

\section{Study Area}

This study used data from the $2^{\text {nd }}$ National Program for Access and Quality Improvement in Primary Care ( $2^{\text {nd }}$ PMAQ-AB cycle) in Brazil, an external evaluation cycle held between 2013 and 2014. This survey was conducted by the Brazilian Ministry of Health in 5,211 cities throughout the country, including the 27 state capitals, representing $93.5 \%$ of Brazilian cities. The 30,424 primary care teams that joined the program were evaluated, corresponding to almost $90 \%$ of all primary care teams in the country. Further details about the National Program for Access and Quality Improvement in Primary Care in Brazil have been previously reported ${ }^{21,22}$. 


\section{Data Sources}

Prenatal care, demographic and social characteristics data were obtained from the National Program for Access and Quality Improvement in Primary Care (PMAQ-AB) database, second external evaluation. More specifically, we analyzed the answers of users interviewed in Brazil in Module III - Interview with users in the health services, which investigates user's perception and satisfaction regarding use and access.

\section{Study Population and Sample}

The study population comprises the Brazilian public health system users assessed in PMAQ-AB. About 114,615 users were interviewed. This study population consisted of 13,020 female users who met the following criteria: not being assisted for the first time, not having spent more than 12 months without service, and with children up to 2 years old.

\section{Variables}

The dependent variables were: performing prenatal care in the unit, primary health services, number of prenatal appointments, performing HIV and VDRL tests.

The criteria for assessing the prenatal care were based on the protocols of the Ministry of Health. These protocols recommend that prenatal care should begin by the $12^{\text {th }}$ gestational week $^{23}$, with a minimum of six appointments during follow-up and performing HIV serological and Venereal Disease Research Laboratory (VDRL) tests.

The independent variables are related to demographic and social characteristics of women who had prenatal care in primary health services. These variables were obtained from a questionnaire, which included: age, race, formal education level, work and participation in the Bolsa Família conditional cash transfer program. These variables are representative of these women's socioeconomic position and show how this position can affect the health service access distribution.

\section{Statistical Analysis}

The three outcomes were initially analyzed according to the independent variables. The prevalence is shown in absolute and relative values of each category, and the effect was estimated through the prevalence ratios (PR) and their respective confidence intervals of 95\% (95\%CI). Variables with significant associations in this bivariate analysis were fit in a Poisson multiple regression analysis with robust variance to obtain adjusted estimates.

\section{Ethical Issues}

This study was based on secondary data from publicly available datasets (http://dab.saude. gov.br/portaldab/ape_pmaq.php), and therefore did not require ethical approval. The individual data were obtained from the public database of the National Program for Access and Quality Improvement in Primary Care (PMAQ-AB), approved by the Ethics Committee of the Federal University of Rio Grande do Sul under the Protocol 21,904. Patient information was anonymous and de-identified prior to analysis.

\section{RESULTS}

From the 13,020 women participating in this study, $76.4 \%(9,945)$ had prenatal care in the primary health services unit, while $23.6 \%(3,075)$ did not receive prenatal care in the service, and were therefore excluded from this study as they did not fit the analysis scope. The answers "I do not know" or "not answered" were also excluded.

Table 1 shows descriptive analysis results of the dependent variables compared with demographic and social characteristics. The women that had six or more prenatal appointments are mostly white, over 30 years old, with less than eight years of study and 
Table 1. Bivariate associations between prenatal care, HIV and syphilis tests and maternal demographic and social characteristics. Brazil,2014.

\begin{tabular}{|c|c|c|c|c|c|c|c|c|c|}
\hline \multirow{2}{*}{ Variable } & \multicolumn{2}{|c|}{ Prenatal appointments $(\mathrm{n}=\mathbf{8}, 238)$} & \multirow{2}{*}{$\mathbf{p}$} & \multicolumn{2}{|c|}{ HIV test $(n=9,749)$} & \multirow[b]{2}{*}{ p } & \multicolumn{2}{|c|}{ VDRL test $(n=8,904)$} & \multirow{2}{*}{$\mathbf{p}$} \\
\hline & $<5(\%)$ & $\geq 6(\%)$ & & Yes $(\%)$ & No $(\%)$ & & Yes $(\%)$ & No $(\%)$ & \\
\hline \multicolumn{10}{|l|}{ Age (years) } \\
\hline 15-19 & 19.4 & 80.6 & 0.171 & 92.0 & 8.0 & 0.000 & 78.9 & 21.1 & $<0.001$ \\
\hline $20-29$ & 17.9 & 82.1 & & 94.5 & 5.5 & & 86.9 & 13.1 & \\
\hline$\geq 30$ & 16.8 & 83.2 & & 96.5 & 3.5 & & 91.8 & 8.2 & \\
\hline \multicolumn{10}{|l|}{ Race } \\
\hline White & 17.1 & 82.9 & 0.438 & 96.3 & 3.7 & $<0.001$ & 89.8 & 10.2 & $<0.001$ \\
\hline Non White & 17.9 & 82.1 & & 94.3 & 5.7 & & 86.7 & 13.3 & \\
\hline \multicolumn{10}{|c|}{ Years of schooling } \\
\hline$\geq 8$ & 20.5 & 79.5 & $<0.001$ & 92.0 & 8.0 & $<0.001$ & 38.2 & 52.3 & $<0.001$ \\
\hline$<8$ & 16.7 & 83.3 & & 96.0 & 4.0 & & 61.8 & 47.7 & \\
\hline \multicolumn{10}{|l|}{ Work } \\
\hline Yes & 17,5 & 82.5 & 0.742 & 95.8 & 4.2 & 0.016 & 90.0 & 10.0 & $<0.001$ \\
\hline No & 17,8 & 82.2 & & 94.5 & 5.5 & & 86.6 & 13.4 & \\
\hline \multicolumn{10}{|c|}{ Cash transfer programme } \\
\hline Yes & 16.2 & 83.8 & $<0.001$ & 93.7 & 6.3 & $<0.001$ & 86.0 & 14.0 & $<0.001$ \\
\hline No & 19.2 & 80.8 & & 95.9 & 4.1 & & 88.7 & 11.3 & \\
\hline
\end{tabular}

VDRL: Venereal Disease Research Laboratory

participant in the cash transfer program. Women who had up to five prenatal appointments were predominantly non-white, between 15 and 19 years old, with more than eight years of study and not participant in the cash transfer program. Significant differences regarding formal education and cash transfer program participants were observed.

The coverage rate for the HIV testing was $94.8 \%$. The percentual is higher in white women over 30 years old, with less than eight years of study and not a cash transfer program participant. Women that did not undergo the anti-HIV test were predominantly non-white, between 15 and 19 years old, with less than 8 years of study and a cash transfer program participant. Apart from work, all demographic and social characteristics resulted in significant associations. The syphilis testing coverage rate was $87.5 \%$, and the bivariate analysis results were quite similar (Table 1) to the HIV testing. The outcome of performing tests for syphilis detection during prenatal care were significantly associated with all demographic and social characteristics.

Tables 2, 3 and 4 show Poisson regression results to the outcomes of prenatal care and the demographic and social characteristics. A statistically significant association with the variables "less than eight years of study" ( $P R=1.31 ; 95 \% C I 1.19-1.45 ; \mathrm{p}<0.001)$ and "participants of the cash transfer program" $(\mathrm{PR}=0.80 ; 95 \% \mathrm{CI} 0.72-0.88 ; \mathrm{p}<0.001)$ was found in the outcome "having less than 6 prenatal care appointments" and individual variables.

The Poisson regression results only showed a statistically significant association of the variable "participants of the cash transfer program" (PR = 1.43; 95\%CI 1.19-1.72; $\mathrm{p}<0.001)$ regarding the outcome of HIV testing absence during prenatal care and demographic and social characteristics. Finally, Poisson regression results also showed a statistically significant association of the variables "less than eight years of study" $(\mathrm{PR}=1.75$; 95\%CI 1.56-1.96; $\mathrm{p}<0.001)$ and "participants of the cash transfer program" ( $\mathrm{PR}=1.21$; 95\%CI 1.07-1.36; $\mathrm{p}<0.001$ ) when compared syphilis testing absence during prenatal care and demographic and social characteristics.

\section{DISCUSSION}

This study assessed the individual determinants of HIV and syphilis testing access during prenatal care in Brazil. From the implementation of the Rede Cegonha (Stork Network) starting in 2011, the prenatal care provides rapid HIV and syphilis testing. Prenatal care 
Table 2. Results of Poisson multiple regression analysis for the outcome "having less than 6 prenatal care appointments" and individual covariates.

\begin{tabular}{|c|c|c|c|c|c|c|}
\hline \multirow{2}{*}{ Covariates } & \multicolumn{2}{|c|}{ Less than 6} & \multicolumn{2}{|c|}{ Non-adjusted } & \multicolumn{2}{|c|}{ Adjusted } \\
\hline & $\mathbf{n}$ & $\%$ & PR $(95 \% \mathrm{Cl})$ & p & PR $(95 \% \mathrm{CI})$ & $\mathbf{p}$ \\
\hline \multicolumn{7}{|l|}{ Age (years) } \\
\hline $15-19$ & 203 & 19.4 & 1 & & & \\
\hline $20-29$ & 839 & 17.9 & $0.93(0.81-1.06)$ & 0.143 & & \\
\hline$\geq 30$ & 422 & 16.8 & $0.87(0.75-1.00)$ & 0.034 & & \\
\hline \multicolumn{7}{|l|}{ Race/Color } \\
\hline White & 391 & 17.1 & 1 & & & \\
\hline Non-White & 1,030 & 17.9 & $1.04(0.94-1.16)$ & 0,438 & & \\
\hline \multicolumn{7}{|c|}{ Years of schooling } \\
\hline$\geq 8$ & 971 & 16.7 & 1 & & 1 & \\
\hline$<8$ & 493 & 20.5 & $1.23(1.12-1.36)$ & $<0.001$ & $1.31(1.19-1.45)$ & $<0.001$ \\
\hline \multicolumn{7}{|l|}{ Work } \\
\hline Yes & 347 & 17.5 & 1 & & & \\
\hline No & 1,117 & 17.8 & $1.02(0.91-1.13)$ & 0.371 & & \\
\hline \multicolumn{7}{|c|}{ Cash transfer programme } \\
\hline No & 820 & 19.2 & 1 & & 1 & \\
\hline Yes & 642 & 16.2 & $0.84(0.77-0.93)$ & $<0.001$ & $0.80(0.72-0.88)$ & $<0.001$ \\
\hline
\end{tabular}

Table 3. Results of Poisson multiple regression analysis for the outcome "do not perform HIV tests during prenatal care" and individual covariates.

\begin{tabular}{|c|c|c|c|c|c|c|}
\hline \multirow{2}{*}{ Covariates } & \multicolumn{2}{|c|}{ No HIV tests } & \multicolumn{2}{|c|}{ Non-adjusted } & \multicolumn{2}{|c|}{ Adjusted } \\
\hline & $\mathbf{n}$ & $\%$ & PR $(95 \% \mathrm{Cl})$ & $\mathbf{p}$ & PR $(95 \% \mathrm{Cl})$ & $\mathbf{p}$ \\
\hline \multicolumn{7}{|l|}{ Age (years old) } \\
\hline $15-19$ & 97 & 8.0 & 1 & & 1 & \\
\hline $20-29$ & 302 & 5.5 & $0.69(0.55-0.86)$ & $<0.001$ & $0.65(0.52-0.82)$ & \\
\hline$\geq 30$ & 106 & 3.5 & $0.43(0.33-0.57)$ & $<0.001$ & $0.37(0.28-0.49)$ & \\
\hline \multicolumn{7}{|l|}{ Race/Color } \\
\hline White & 104 & 3.7 & 1 & & 1 & \\
\hline Non-White & 386 & 5.7 & $1.53(1.24-1.89)$ & $<0.001$ & $1.36(1.10-1.69)$ & \\
\hline \multicolumn{7}{|c|}{ Years of schooling } \\
\hline$\geq 8$ & 281 & 4.0 & 1 & & 1 & \\
\hline$<8$ & 223 & 8.0 & $1.97(1.66-2.34)$ & $<0.001$ & $1.91(1.59-2.29)$ & \\
\hline \multicolumn{7}{|l|}{ Work } \\
\hline Yes & 103 & 4.2 & 1 & & & \\
\hline No & 402 & 5.5 & $1.30(1.05-1.60)$ & 0.016 & & \\
\hline \multicolumn{7}{|c|}{ Cash transfer programme } \\
\hline No & 213 & 4.1 & 1 & & 1 & \\
\hline Yes & 290 & 6.3 & $1.53(1.28-1.81)$ & $<0.001$ & $1.43(1.19-1.72)$ & $<0.001$ \\
\hline
\end{tabular}

is an important opportunity to diagnose these diseases, providing both prevention of mother-to-child transmission (PMTCT) and access of pregnant women and their partners to available care practices in order to reduce morbidity and mortality from these diseases in the adult population ${ }^{24}$.

The strategy for eliminating congenital syphilis was launched by the WHO in $2007^{4}$ and reinforced in $2012^{6}$, when the integration of the prevention of mother-to-child transmission of HIV and congenital syphilis program during prenatal care was recommended. The Pan American Health Organization's goals ${ }^{25}$ are to reduce mother-to-child transmission of HIV (MTCT) to $\leq 2 \%$ and its incidence to $\leq 0.3$ cases per 1,000 live births. In addition, a reduction in the congenital syphilis incidence to less than 0.5 cases per 1,000 live births. These targets have been adopted by the Brazilian Ministry of Health. Twenty-two (22) countries in the Americas reported a similar number in 2015 regarding achieving the goal of eliminating MTCT of $\mathrm{HIV}^{2}$. 
Table 4. Results of Poisson multiple regression analysis for the outcome "do not perform tests for syphilis detection during prenatal care" and individual covariates.

\begin{tabular}{|c|c|c|c|c|c|c|}
\hline \multirow{2}{*}{ Covariates } & \multicolumn{2}{|c|}{ No syphilis test } & \multicolumn{2}{|c|}{ Non-adjusted } & \multicolumn{2}{|c|}{ Adjusted } \\
\hline & $\mathbf{n}$ & $\%$ & PR $(95 \% \mathrm{Cl})$ & $\mathbf{p}$ & PR $(95 \% \mathrm{Cl})$ & $\mathbf{p}$ \\
\hline \multicolumn{7}{|l|}{ Age (years old) } \\
\hline $15-19$ & 231 & 21.1 & 1 & & & \\
\hline $20-29$ & 657 & 13.1 & $0.62(0.54-0.71)$ & $<0.001$ & $0.61(0.53-0.70)$ & $<0.001$ \\
\hline$\geq 30$ & 229 & 8.2 & $0.39(0.33-0.46)$ & $<0.001$ & $0.36(0.30-0.43)$ & $<0.001$ \\
\hline \multicolumn{7}{|l|}{ Race/Color } \\
\hline White & 260 & 10.2 & 1 & & 1 & \\
\hline Non-White & 824 & 13.3 & $1.30(1.14-1.49)$ & $<0.001$ & $1.19(1.05-1.36)$ & 0.008 \\
\hline \multicolumn{7}{|c|}{ Years of schooling } \\
\hline$\geq 8$ & 669 & 10.4 & 1 & & 1 & \\
\hline$<8$ & 447 & 18.1 & $1.74(1.56-1.95)$ & $<0.001$ & $1.75(1.56-1.96)$ & $<0.001$ \\
\hline \multicolumn{7}{|l|}{ Work } \\
\hline Yes & 223 & 10.0 & 1 & & & \\
\hline No & 894 & 13.4 & $1.34(1.17-1.54)$ & $<0.001$ & & \\
\hline \multicolumn{7}{|c|}{ Cash transfer programme } \\
\hline No & 539 & 11.3 & 1 & & 1 & \\
\hline Yes & 576 & 14.0 & $1.24(1.11-1.38)$ & $<0.001$ & $1.21(1.07-1.36)$ & 0.001 \\
\hline
\end{tabular}

In Brazil, the policy proposes an integration between maternal health care and childcare by the protocols of HIV and syphilis ${ }^{9}$ and the Rede Cegonh ${ }^{26}$ Program to prevent vertical transmission. The elimination of mother-to-child transmission of both HIV and syphilis requires early access to quality prenatal care for all pregnant women. Although most women in this study have had six or more prenatal care appointments, it did not ensure HIV and syphilis testing performance, which shows missed opportunity of prevention during prenatal care. The proportion found in this study may be underestimated by the difficulty in reporting this information, especially in women with lower education level. One study pointed out that some pregnant women or mothers may overestimate their performance of the appointments to demonstrate carefulness ${ }^{27}$. On the other hand, studies checking pregnant women's health cards revealed problems in information recording, which may cause underreporting ${ }^{27-29}$.

A Brazilian cohort study using data from the pregnant woman's health card, medical records and interviews showed that black or brown women with lower education level and those who attended public health services had less syphilis and HIV testing coverage, and these were the women with the highest prevalence of syphilis during pregnancy ${ }^{30}$. Another study revealed social inequalities in prenatal care. Non-white women with lower education level and family income start the prenatal care later and, when they have access, it is of poor quality ${ }^{31}$.

On the other hand, the number of prenatal appointments of six or more per pregnancy potentially reflects an increase in access to primary health care with the Family Health Program in Brazil ${ }^{32}$, and a more equitable health service use ${ }^{33}$ in areas covered by the program. Our findings showed that non-white younger women attend fewer prenatal appointments. An increase in the number of women with children under 20 years old that had syphilis during pregnancy was observed in the historical series of cases of congenital syphilis and syphilis in pregnant women from 2005 to 2017 in Brazil, suggesting a greater probability of having recent forms and higher transmission of syphilis in this age group ${ }^{34}$. This result is important for health management and action service implementation aimed at this vulnerable population.

Less-educated women and participants in the cash transfer program had the syphilis testing lowest coverage rate, while the HIV testing lowest coverage rate was among women participating in the cash transfer program. Some studies ${ }^{35,36}$ reported low education 
as a congenital syphilis and HIV perinatal infection predictor. This suggests missed opportunities for diagnosis and intervention among women with increased risk of vertical syphilis and HIV transmission.

We observed in this study that receiving the family financial assistance (Bolsa Familia) was insufficient to prevent inequalities in access to testing for these diseases. On the other hand, receiving family financial assistance was associated with a greater number of appointments, which suggests financial difficulties to access the testing within the primary care services. National studies indicate failures in prenatal care regarding syphilis and HIV control, with missed opportunities for diagnosis and treatment ${ }^{13,26,32}$.

Studies in other countries showed missed opportunities in testing of HIV and infection by syphilis $^{30}$ during pregnancy ${ }^{37}$, and the importance of an integrated program to ensure that HIV and syphilis testing are offered and performed on all pregnant women ${ }^{38,39}$. In Brazil, structural problems in diagnostic support services and delays in result returning seem to be the main limitations for achieving $100 \%$ coverage of pregnant women for VDRL and HIV tests ${ }^{13}$.

Some weaknesses have been pointed out by the Ministry of Health, among which are: the increase in the discovery of cases due to the availability of rapid care tests; penicillin shortages; the reference to other levels attention by of the almost half of primary health care units, thus losing patient for not treating ${ }^{3}$.

The main challenge for congenital syphilis control is the timely diagnosis in pregnancy ${ }^{40}$. Congenital syphilis can be largely prevented with inexpensive pregnant mother penicillin treatment if/when correctly diagnosed ${ }^{41}$. Its vertical transmission cannot be prevented with measures adopted at birth, requiring the services to diagnose and treat infection during pregnancy. Regarding HIV, care measures can be adopted to avoid diagnosis only occurring late in pregnancy or upon admission for delivery ${ }^{42}$.

Some authors recommend the use of rapid tests carried out in health units for pregnant women with limited access to health services, which would allow a more timely intervention ${ }^{8,43}$. However, implementing rapid tests in primary care is still difficult ${ }^{19,20,21}$.

This study has some strengths and limitations. A strength is the completeness of the survey with national coverage in primary health care from which the data were extracted. However, the findings must be interpreted with some limitation considerations.

This study presents a cross-sectional design analysis of data. However, it does not enable the determination of cause and effect. The data were collected from a non-probability convenience sample of patients. Moreover, a possible selection bias cannot be excluded regarding women included in this study, since only women who had prenatal care in the evaluated primary health care facilities were considered. Firstly, having a child up to two years old was used as a proxy for gestation, which excluded women who had fetal losses and miscarriages in this period. Secondly, a memory bias also due to children's age limit. National studies evaluating the maternal reporting reliability and pregnant women's cardiac records show that both methods have limitations ${ }^{28-30}$. Underreporting was observed in the use of health cards by the pregnant women such as incomplete cards and, in some cases, cards left at the services, which hinders interprofessional actions. Registry absence suggests non-performance of procedures.

Despite these study limitations, this large-scale study provides useful insights into prenatal care, and HIV and syphilis testing during pregnancy. Further studies are necessary to improve our understanding of the complex dynamics of mother-to-child transmission of both HIV and syphilis in this population.

Although there has been an increase in prenatal coverage, and that most pregnant women in this study had access to six or more prenatal care appointments, the findings show missed opportunities for diagnosing HIV and syphilis infection during prenatal care. This was 
associated with individual socioeconomic position, especially education level in Brazilian pregnant women and indicate weaknesses in the quality of maternal health care services to eliminate mother-to-child transmission.

Therefore, improving service organization is necessary to increase the syphilis and HIV control program effectiveness. Quality improvement in these programs could make a difference in reducing maternal and infant morbidity and mortality caused by both syphilis and HIV.

\section{REFERENCES}

1. Joint United Nations Programme on HIV/AIDS. 2015 Progress report on the Global Plan. Geneva: UNAIDS; 2015.

2. Pan American Health Organization. Elimination of mother-to-child transmission of HIV and syphilis in the Americas: update 2016. Washington, DC: PAHO; 2017.

3. Boletim Epidemiológico -Sífilis. Brasília, DF: Ministério da Saúde, Secretaria de Vigilância em Saúde; 2016;47(35).

4. World Health Organization, Department of Reproductive Health and Research. The global elimination of congenital syphilis: rationale and strategy for action. Geneva: WHO; 2007.

5. World Health Organization, Department of Reproductive Health and Research. Investment case for eliminating congenital syphilis: promoting better maternal and child health outcomes and stronger health systems. Geneva: WHO; 2012.

6. World Health Organization. HIV operational plan 2012-2013. WHO's support to implement the Global health sector strategy on HIV/AIDS. Geneva: WHO; 2012.

7. Gloyd S, Montoya P, Floriano F, Chadreque MC, Pfeiffer J, Gimbel-Sherr K. Scaling up antenatal syphilis screening in Mozambique: transforming policy to action. Sex Transm Dis. 2007;34(7 Suppl):S31-6. https://doi.org/10.1097/01.olq.0000264586.49616.72

8. Schackman BR, Neukermans CP, Fontain SN, Nolte C, Joseph P, Fitzgerald DW. Costeffectiveness of rapid syphilis screening in prenatal HIV testing programmes in Haiti. PLoS Med. 2007;4(5):e183. https://doi.org/10.1371/journal.pmed.0040183

9. Ministério da Saúde (BR), Secretaria de Vigilância em Saúde. Programa Nacional de DST e AIDS. Protocolo para a prevenção da transmissão vertical de HIV e sífilis: manual de bolso. Brasília, DF; 2007. (Série B. Textos Básicos de Saúde).

10. Ramos Jr AN, Matida LH, Saraceni V, Veras MASM, Pontes RJS. Control of mother-to-child transmission of infectious diseases in Brazil: progress in HIV/Aids and failure in congenital syphilis. Cad Saude Publica. 2007;23 Supl 3:S370-8. https://doi.org/10.1590/S0102-311X2007001500005

11. Veloso VG, Portela MC, Vasconcellos MTL, Matzenbacher LA, Vasconcelos ALR, Grinsztejn B, et al. HIV testing among pregnant women in Brazil: rates and predictors. Rev Saude Publica. 2008;42(5):859-67. https://doi.org/10.1590/S0034-89102008000500011

12. Soeiro CMO, Miranda AE, Saraceni V, Lucena NO, Talhari S, Ferreira LCL. Mother-to-child transmission of HIV infection in Manaus, State of Amazonas, Brazil. Rev Soc Bras Med Trop. 2011;44(5):537-41. https://doi.org/10.1590/S0037-86822011000500001

13. Domingues RMS, Saraceni V, Hartz ZMA, Leal MC. Congenital syphilis: a sentinel event in antenatal care quality. Rev Saude Publica. 2013;47(1):147-57. https://doi.org/10.1590/S0034-89102013000100019

14. Gouveia PAC, Silva GAP, Albuquerque MFPM. Factors associated with mother-to-child transmission of the human immunodeficiency virus in Pernambuco, Brazil, 2000-2009. Trop Med Int Health. 2013;18(3):276-85. https://doi.org/10.1111/tmi.12042

15. Nunes PS, Zara ALSA, Rocha DFNC, Marinho TA, Mandacarú PMP, Turchi MD. Syphilis in pregnancy and congenital syphilis and their relationship with Family Health Strategy coverage, Goiás, Brazil, 2007-2014: an ecological study. Epidemiol Serv Saude. 2018;27(4):1-10. https://doi.org/10.5123/s1679-49742018000400008

16. Araújo EC, Monte PCB, Haber ANCA. [Evaluation of prenatal care for syphilis and HIV detection in pregnant women attended in a rural area of Pará State, Brazil]. Rev Pan-Amaz Saude. 2018;9(1):33-9. Portuguese. https://doi.org/10.5123/s2176-62232018000100005 
17. Anversa ETR, Bastos GANI, Nunes LN, Dal Pizzol TS. [Quality of prenatal care: traditional primary care and Family Health Strategy units in a city in southern Brazil]. Cad Saude Publica. 2012;28(4):789-800. Portuguese. https://doi.org/10.1590/S0102-311X2012000400018

18. Araújo CL, Shimizu HE, Sousa AIA, Hamann EM. Incidence of congenital syphilis in Brazil and its relationship with the Family Health Strategy. Rev Saude Publica. 2012;46(3):479-86. https://doi.org/10.1590/S0034-89102012000300010

19. Lopes ACMU, Araújo MAL, Vasconcelos LDPG, Uchoa FSV, Rocha HP, Santos JR. Implementation of fast tests for syphilis and HIV in prenatal care in Fortaleza - Ceará. Rev Bras Enferm. 2016;69(1):54-8. https://doi.org/10.1590/0034-7167.2016690108i

20. Costa CC, Freitas LV, Sousa DMN, Oliveira LL, Chagas ACMA, Lopes MVO, et al. Congenital syphilis in Ceará: epidemiological analysis of one decade. Rev Esc Enferm USP. 2013;47(1):152-9. https://doi.org/10.1590/S0080-62342013000100019

21. Ministério da Saúde (BR), Secretaria de Atenção à Saúde, Departamento de Atenção Básica. Programa Nacional de Melhoria do Acesso e da Qualidade da Atenção Básica (PMAQ-AB). Saúde mais perto de você: acesso e qualidade: documento síntese para avaliação externa. Brasília, DF; 2012.

22. Pinto HA, Sousa ANA, Ferla AA. [The National Program for Access and Quality Improvement in Primary Care: faces of an innovative policy]. Saude Debate. 2014;38 Spec No:358-72. Portuguese. https://doi.org/10.5935/0103-1104.2014S027

23. Ministério da Saúde (BR), Secretaria de Atenção à Saude, Departamento de Ações Programáticas Estratégicas, Área Técnica de Saúde da Mulher. Pré-natal e puerpério: atenção qualificada e humanizada: manual técnico. Brasília, DF; 2006. (Série A. Normas e Manuais Técnicos); (Série Direitos Sexuais e Direitos Reprodutivos, Caderno, 5).

24. Hogan MC, Foreman KJ, Naghavi M, Ahn SY, Wang M, Makela SM, et al. Maternal mortality for 181 countries, 1980-2008: a systematic analysis of progress towards Millennium Development Goal 5. Lancet. 2010;375(9726):1609-23. https://doi.org/10.1016/S0140-6736(10)60518-1

25. Pan American Health Organization. Regional Initiative for the Elimination of Mother-to-Child Transmission of HIV and Congenital Syphilis in Latin America and the Caribbean: regional monitoring strategy. 2.ed. Washington, DC: PAHO; 2013.

26. Ministério da Saúde (BR). Portaria No 1.429, de 24 junho de 2011. Institui no âmbito do Sistema Único de Saúde - SUS, a Rede Cegonha. Brasília, DF; 2011.

27. Zanchi M, Gonçalves CV, Cesar JA, Dumith SC. [Agreement between data from prenatal care cards and maternal recall in a medium-sized Brazilian city]. Cad Saude Publica. 2013;29(5):1019-28. Portuguese. https://doi.org/10.1590/S0102-311X2013000500019

28. Barreto FDFP, Albuquerque RM. [Discrepancies between verbal information and the records in pregnant woman card, a neglected instrument]. Rev Bras Ginecol Obstet. 2012;34(6):259-67. Portuguese. https://doi.org/10.1590/S0100-72032012000600004

29. Santos Neto ET, Leal MC, Oliveira AE, Zandonade E, Gama SGN. [Agreement between information from the Pregnant Card and the mother's memory of antenatal care]. Cad Saude Publica. 2012;28(2):256-66. Portuguese. https://doi.org/10.1590/S0102-311X2012000200005

30. Domingues RMSM, Szwarcwald CL, Souza Junior PRB, Leal MC. Prevalence of syphilis in pregnancy and prenatal syphilis testing in Brazil: Birth in Brazil study. Rev Saude Publica. 2014;48(5):766-74. https://doi.org/10.1590/S0034-8910.2014048005114

31. Gonçalves CV, Cesar JA, Mendoza-Sassi RA. [Quality and equity in prenatal care: a population- based study in Southern Brazil]. Cad Saude Publica. 2009;25(11):2507-16. Portuguese. https://doi.org/10.1590/S0102-311X2009001100020

32. Macinko J, Lima-Costa MF. Horizontal equity in health care utilization in Brazil, 1998-2008. Int J Equity Health. 2012;11:33. https://doi.org/10.1186/1475-9276-11-33

33. Fernandes LCL, Bertoldi AD, Barros AJD. Health service use in a population covered by the Estratégia de Saúde da Família (Family Health Strategy). Rev Saude Publica. 2009;43(4):595-603. https://doi.org/10.1590/S0034-89102009005000040

34. Boletim Epidemiológico. Brasília, DF: Ministério da Saúde, Secretaria de Vigilância em Saúde; 2017;48(36).

35. Thompson BL, Matuszak D, Dwyer DM, Nakashima A, Pearce H, Israel E. Congenital syphilis in Maryland, 1989-1991: the effect of changing the case definition and opportunities for prevention. J Sex Transm Dis. 1995;22(6):364-9. 
36. Souza Júnior PRB, Szwarcwald CL, Barbosa Júnior A, Carvalho MF, Castilho EA. [HIV infection during pregnancy: the Sentinel Surveillance Project, Brazil, 2002]. Rev Saude Publica. 2004;38(6):764-72. Portuguese. hhttps://doi.org/10.1590/S0034-89102004000600003

37. Trepka MJ, Bloom SA, Zhang G, Kim S, Nobles RE. Inadequate syphilis screening among women with prenatal care in a community with a high syphilis incidence. J Sex Transm Dis. 2006;33(11):670-4. https://doi.org/10.1097/01.olq.0000216032.52731.ea

38. Larsson EC, Thorson AE, Parlyo G, Waiswa P, Kodobera D, Marrone G, et al. Missed opportunities: barriers to HIV testing during pregnancy from a population based cohort study in rural Uganda. PloS One. 2012;7(8):e37590. https://doi.org/10.1371/journal.pone.0037590

39. Balira R, Mabey D, Weiss H, Ross DA, Changalucha J Watson-Jones D. The need for further integration of services to prevent mother-to-child transmission of HIV and syphilis I Mwanza city, Tanzania. Int J Gynaecol Obstet. 2015;130 Suppl 1:S51-7. https://doi.org/10.1016/j.ijgo.2015.04.016

40. Owiredu MN, Newman L, Nzomo T, Kafando GC, Sanni S, Shaffer N, et al. Elimination of mother-to-child transmission of HIV and syphilis: a dual approach in the African region to improve quality of antenatal care and integrated disease control. Int J Gynecol Obstet. 2015;130 Suppl 1:S27-31. https://doi.org/10.1016/j.ijgo.2015.04.010

41. Blencowe H, Cousens S, Kamb M, Berman S, Lawn JE. Lives Saved Tool supplement detection and treatment of syphilis in pregnancy to reduce syphilis related stillbirths and neonatal mortality. BMC Public Health. 2011;11 Suppl 3:S9. https://doi.org/10.1186/1471-2458-11-S3-S9

42. Peeling RW, Mabey D, Fitzgerald DW, Watson-Jones D. Avoiding HIV and dying of syphilis. Lancet. 2004;364(9445):1561-3. https://doi.org/10.1016/S0140-6736(04)17327-3

43. Ramos Jr AN, Matida LH, Saraceni V, Veras MASM, Pontes RJS. Control of mother-to-child transmission of infectious diseases in Brazil: progress in HIV/AIDS and failure in congenital syphilis. Cad Saude Publica. 2007;23 Supl 3:S370-8. https://doi.org/10.1590/S0102-311X2007001500005

Funding: Conselho Nacional de Desenvolvimento Científico e Tecnológico (CNPq) (Grant number 206607/2014-8)

Authors' Contributions: Design and planning of the study: CHSMF, SMFD. Collection, analysis, and interpretation of the data: AGR. Preparation or review of the study: CHSMF, MHRG, FDSF, AAC, SMFD. Approval of the final version: CHSMF, AGR, MHRG, FDSF, AAC, SMFD. All authors take public responsibility for the content of the article.

Conflict of Interest: The authors declare no conflict of interest. 